\title{
Las emociones del futuro profesorado de secundaria de ciencias y matemáticas, tras un programa de intervención
}

\author{
Ana Belén Borrachero ${ }^{1}$, María Antonia Dávila ${ }^{2}$, Emilio Costillo ${ }^{2}$, Vicente \\ Mellado $^{2}$ \\ ${ }^{1}$ Facultad de Educación, Departamento de Psicología de la Educación y Psicobiología, \\ Universidad Internacional de La Rioja (UNIR). Badajoz, España. \\ ${ }^{2}$ Facultad de Educación, Departamento de Didáctica de las Ciencias Experimentales y de \\ las Matemáticas, Universidad de Extremadura. Badajoz, España.
}

[Recibido el 13 de marzo de 2017, aceptado el 15 de mayo de 2017]

La literatura indica que los futuros profesores, cuando comienzan sus prácticas docentes, arrastran consigo una serie de creencias, actitudes y emociones, resultado del recuerdo de sus diversos años de escolarización. Por tanto, se considera necesario que los profesores en formación reflexionen sobre las emociones que experimentan hacia las ciencias. Para ello, se diseña y se desarrolla un programa de intervención para alumnos del Máster Universitario de Formación del Profesorado de Educación Secundaria, en las especialidades de Biología/Geología, Física/Química y Matemáticas. Los resultados demuestran que al terminar el programa, de forma general, las emociones que experimentan son positivas, existiendo una ausencia de emociones negativas. Además, su autoeficacia docente ha aumentado y saben utilizar estrategias para autorregularse.

Palabras clave: emociones; profesores en formación; ciencias; Educación Secundaria; programa de intervención.

\section{The emotions of future secondary teachers of science and mathematics, after an intervention program}

Literature indicates that future teachers, when they begin their teaching practices, carry with them a series of beliefs, attitudes and emotions, a result of the memory of their different years of schooling. Therefore, it is considered necessary that the teachers in formation reflect on the emotions that they experience towards the sciences. To this end, an intervention program is designed and developed for students of the Master's Degree in Teacher Training in Secondary Education, in the areas of Biology / Geology, Physics / Chemistry and Mathematics. The results show that at the end of the program, in general, the emotions that they experience are positive and there is an absence of negative emotions. In addition, their teaching self-efficacy has increased and they know how to use strategies to self-regulate.

Keywords: emotions; pre-service teachers; Science; Secondary Education; intervention program

Para citar el artículo. Borrachero, A. B., Dávila, M. A., Costillo, E. y Mellado, V. (2017). Las emociones del futuro profesorado de secundaria de ciencias y matemáticas, tras un programa de intervención. Ápice. Revista de Educación Científica, 1(1), 17-39. DOI: https://doi.org/ 10.17979/arec.2017.1.1.2008

Contacto.belenborrachero@hotmail.com,madavilaacedo@unex.es,costillo@unex.es, vmellado@unex.es 


\section{Introducción}

La continua necesidad de mejorar la calidad de la enseñanza y del aprendizaje conlleva principalmente la adaptación del profesorado, que ha de contar con las competencias profesionales necesarias para el ejercicio de los diferentes puestos docentes. Este hecho lleva implícito una dificultad, pues las demandas de la sociedad a las necesidades emergentes son cada día más complejas (Gutiérrez, 2011).

La formación inicial del profesorado de Educación Secundaria Obligatoria ha sido, y lo seguirá siendo, un tema discutido en el sistema educativo, en relación al modelo que se sigue, la duración de los cursos, el nivel académico de los integrantes y los contenidos que se utilizan para la formación del futuro profesor. No hay que olvidar que en España siempre ha predominado la especialización en una disciplina, por tanto los docentes de Secundaria han sido durante años licenciados universitarios con pequeñas nociones en formación didáctica (De Puelles, 2003). Las licenciaturas o grados de Biología, Geología, Física y Química están más orientadas a la empresa o a la investigación que a la docencia en Secundaria, a la que siguen considerando una salida de segundo orden (García y Martínez, 2001) Estas carreras están además dirigidas a una de las materias y apenas dan formación en las demás. Puede ocurrir que un profesor de la materia de Física y Química (ESO) sea graduado en Física y no haya cursado en su formación universitaria ninguna asignatura de Química.

La falta de conocimiento de la materia que tiene que enseñar genera en el profesor una falta de confianza e inseguridad, haciéndole más dependiente del libro de texto y de la mera memorización de los contenidos (Jarvis y Pell, 2004; Lee, 1995). Además, tendrá dificultades para realizar cambios didácticos y actividades innovadoras, reforzando los modelos tradicionales de enseñanza (Tobin, 1998) que dan al profesor mayor control de la clase y evitan las preguntas incómodas del alumnado (Harlen y Holroyd, 1997). A todo esto, se une la falta de interés y de tiempo dedicado a las materias que no domina y en las que se sienten menos eficaces (Smith y Neale, 1989), repercutiendo en su enseñanza y en el aprendizaje de su alumnado (Huinker y Madison, 1997).

Desde el curso académico 2009/2010, adaptando los estudios al Espacio Europeo de Educación Superior (EEES), el CAP se sustituyó por el Máster Universitario en Formación del Profesorado en Educación Secundaria (en adelante MUFPES), convirtiéndose en un requisito legal para ejercer la profesión de docente de Educación Secundaria. Dicho Máster, tiene una duración de un año, equivalente a 60 créditos destinados a la adquisición de las habilidades y competencias necesarias para ejercer la labor docente en Educación Secundaria. Este paso estaba promovido por la necesidad de formación psicopedagógica y didáctica del nuevo profesorado.

El cambio del CAP al MUFPES es indudablemente positivo para la formación inicial del profesorado, en cuanto a número de horas, contenidos y organización, pero en muchos casos vuelve a existir una desconexión entre teoría y práctica (Solbes y Gavidia, 2013) y entre contenidos científicos básicos y didácticos, lo cual responde a planteamientos congruentes con modelos de formación consecutivos y no integrados (García Barros, 2016). Los contenidos del Máster se encuentran estructurados en torno a módulos de psicopedagogía didáctica y practicum, conocimientos que se consideran fundamentales en la adquisición de competencias y que ayudan a comprender la intervención educativa del profesorado. Son los mismos estudiantes del MUFPES quienes critican la falta de coherencia entre los módulos y las asignaturas, destacando que los contenidos resultan demasiado teóricos en relación a la práctica que realizan en las materias, que 
en ocasiones llega a ser nula. Esto les provoca un estado emocional adverso a las futuras prácticas docentes, donde sobresalen los miedos, las preocupaciones, la ansiedad, el nerviosismo y las bajas creencias de autoeficacia docente y de autoconcepto, solapadas a la incapacidad de autorregulación.

Coincidiendo con Torrecilla, Martínez, Olmos y Rodríguez (2014), el profesor de Educación Secundaria debe ser un educador, no un mero profesional de una materia concreta. Debe ser capaz de trabajar de manera transversal, motivando aprendizajes y competencias relativas a valores, creencias, actitudes y procedimientos.

\section{La intervención metacognitiva y metaemocional}

En los últimos años el número de investigaciones sobre las emociones del profesorado es creciente y está plenamente incluido en la agenda actual de investigación educativa (Mellado et al., 2014), aunque como Uitto, Jokikokko y Estola (2015) reconocen en su revisión del periodo 1985-2014, hacen falta más investigaciones sobre las emociones en la enseñanza y el aprendizaje de contenidos concretos.

Los futuros docentes comienzan el MUFPES con unas concepciones, actitudes y emociones sobre enseñanza y el aprendizaje, formadas durante su propia escolaridad (Désaultes, Larochelle, Gagné y Ruel, 1993; Evans y Fisher, 2000; Pontes y Poyato, 2016). Dichas concepciones están muy arraigadas (Solís, Martín del Pozo, Rivero y Porlán, 2013) y se fundamentan en las experiencias que tuvieron como alumnos, incluyendo características explícitas del currículum, conocimientos de carácter conceptual, procedimental y actitudinal, pero también otros aspectos implícitos, como el recuerdo de sus profesores, el clima social de la clase, y las emociones que les generaron dichas experiencias (Bonil y Márquez, 2011).

Por ende, se considera que el periodo de prácticas se convierte en el momento idóneo para realizar estos programas, pues es en las primeras experiencias docentes cuando más se fijan las rutinas y estrategias de enseñanza, consolidándose concepciones, actitudes y emociones (Delval, 2002), que posteriormente serán difíciles de modificar. Durante su formación los futuros docentes deben reflexionar sobre sus concepciones, actitudes y emociones, así como controlar y autorregular los cambios que se producen en las mismas (Jiménez-Tenorio y Oliva, 2016). Numerosos trabajos con profesorado en formación de primaria y secundaria, señalan que el recuerdo de las emociones sobre el aprendizaje de cada materia en su etapa de estudiantes de secundaria se transfiere en gran parte a lo que sienten al enseñar estas materias durante las prácticas de enseñanza, asociando a las ciencias naturales con emociones mucho más positivas que a la física y química (Borrachero y Brígido, 2011; Borrachero, Brígido, Mellado, Costillo y Mellado, 2014; Brígido, Bermejo, Conde, Borrachero y Mellado, 2010).

Si como señalan Bisquerra y Pérez (2007) los conocimientos académicos se aprenden mejor si los alumnos tienen competencias emocionales, es fundamental formar docentes emocionalmente competentes, que sepan diagnosticar y autorregular sus emociones a través de programas de intervención que incluyan tanto lo cognitivo como lo afectivo. En este sentido, diversos autores señalan la necesidad de la realización de programas de intervención durante la formación inicial del profesorado, donde los componentes cognitivos y afectivos deben desarrollarse simultáneamente (Blanco, Guerrero, Caballero, Brígido y Mellado, 2010; Efklides, 2009; Koballa y Glynn, 2007; Shoffner, 2009). Este tipo de programas suponen un proceso de reflexión sobre la propia experiencia personal como estudiante, pues es en la etapa escolar donde el futuro 
docente ha ido acumulando experiencias afectivos que podrán incidir en su labor como profesional (Alsup, 2005).

La investigación en didáctica de las ciencias, ha dado como fruto la elaboración de algunos programas de formación del profesorado de ciencias, destinados a desarrollar habilidades metacognitivas (Brígido, Borrachero, Bermejo y Dávila, 2014; Copello y Sanmartí, 2001; García y Orozco, 2008; Gunstone y Northfield, 1994; Porlán y Rivero, 1998; White y Mitchell, 1994). Dichas habilidades, favorecen el reconocimiento de las posibles causas de dificultades o problemas en la práctica docente y, a su vez, facilitan la autorregulación de los cambios en los factores afectivos dentro del proceso de enseñar ciencias, y la elaboración de nuevas actividades, materiales y propuestas didácticas (Powell y Anderson, 2002; Sassi, Monroy y Testa, 2005).

Según Brígido (2014), la perspectiva de la metacognición está muy relacionada con un enfoque constructivista de la enseñanza, donde el conocimiento sobre la práctica educativa debe ser un conocimiento creado por el propio docente en formación. El análisis de las experiencias personales es un elemento esencial para promover una enseñanza reflexiva. Esta idea también se encuentra recogida por Pérez, Reyes y Juandó (2001), quienes argumentan que la formación del docente tiene tanto que ver con la propia adquisición de información y conocimiento como con la reflexión sobre su propia actuación, es decir, con el análisis sobre la adecuación de sus propios hábitos de comportamiento docente. La metacognición fomenta la reflexión docente, la comprensión y el seguimiento de lo que piensan, sienten y hacen en su día a día, pero también de los cambios que se ponen en práctica (Bañas, López, Mellado y Ruiz, 2009).

Por tanto, se propone el diseño de un programa de intervención emocional con futuros profesores de ciencias y matemáticas, paralelo a las prácticas docentes, basado en la autorregulación metacognitiva y emocional, promoviendo cambios, tanto en las actitudes y emociones como en las concepciones sobre el aprendizaje y la enseñanza de las ciencias.

El reto de este programa no es sólo formar profesores emocionalmente competentes, que sepan diagnosticar y autorregular sus emociones, y conocer su importancia en la enseñanza y el aprendizaje de las diferentes asignaturas de ciencias y matemáticas, sino también contribuir a dotarles de herramientas que les ayuden a construir un sistema efectivo de autorregulación que les permitirá seguir formándose autónomamente a lo largo de toda su vida profesional (Sanmartí, 2001).

La estrategia que se seguirá durante la intervención se apoya en el tratamiento de situaciones problemáticas de interés que pueden aparecer en el proceso de enseñanza/aprendizaje de las ciencias y matemáticas, reforzando el desarrollo de las prácticas docentes (Fritz, Miller-Heyl, Kreutzer y Macphee, 1995; Furió y Guisasola, 1998; Gil-Pérez et al., 1999; Valdés y Valdés, 1999). Como bien apunta Brígido (2014: 495), basándose en la experiencia de los trabajos anteriores:

"Es necesario partir de situaciones problemáticas abiertas, discutiendo su posible interés y relevancia, procediendo a aproximaciones cualitativas y a la construcción de soluciones tentativas, destinadas a ser puestas a prueba y a integrarse, en su caso, en la futura práctica docente, provocando un cambio metodológico, pero sobre todo actitudinal y emocional".

Si como indica Damasio (2005) el recuerdo de emociones negativas solo puede superarse con emociones positivas aún más fuertes, durante la intervención es necesario provocar emociones positivas hacia la enseñanza y el aprendizaje de las ciencias que 
contrarresten las emociones negativas que pudieran haberse generado a lo largo de la escolaridad (Mellado et al., 2014). Como señala Izquierdo (2013), aprender ciencias debe estar unido al desarrollo de emociones positivas como sorpresa, curiosidad, gratificación o confianza.

\section{Objetivo}

Con el diseño y la realización del programa de intervención, el objetivo que se pretende alcanzar es el siguiente: Determinar y mejorar las emociones al enseñar ciencias de los futuros profesores de secundaria participantes durante la realización del MUFPES, mejorando también su autoeficacia docente y su autorregulación.

\section{Metodología}

La metodología se basa en el diseño de una serie de actividades de estrategias metacognitivas que ayuden al futuro profesorado de ciencias y matemáticas de Secundaria a tomar conciencia de sus emociones y de cómo influyen en el proceso de enseñanza y aprendizaje de su materia. Como apuntan Gil-Pérez y Vilches (2004), las actividades a desarrollar deben incluir los siguientes aspectos:

- La discusión de la posible relevancia e interés de las situaciones que se proponen, dando sentido a su análisis, e intentando evitar que los profesores en formación se encuentren en una situación que les impresione negativamente sin haber podido siquiera formarse una primera idea motivadora o una toma de decisiones.

- El estudio cualitativo de las situaciones problemáticas que se aborden, que ayuden a comprender y mejorar dichas situaciones, a formular preguntas activas sobre lo que se pretende, siendo conscientes de la influencia de los aspectos afectivos.

- La elaboración y el uso de estrategias de resolución de problemas, tanto de tipo cognitivo como afectivo, donde el futuro profesor sea el responsable de su propio aprendizaje y pueda reflexionar sobre los pasos seguidos y de cómo se ha sentido.

- El análisis, argumentación y discusión de los resultados, aunque esto en ocasiones pueda convertirse en un conflicto entre las propias concepciones, actitudes y emociones, pero que favorece el proceso de autorregulación de los futuros profesores.

\section{Muestra}

El programa de intervención lo denominamos Programa de Seguimiento y Apoyo a las Prácticas Docentes (en adelante PSAPD) y se llevó a cabo con estudiantes voluntarios del MUFPES de la Universidad de Extremadura en el curso 2010/2011, los cuales se encontraban distribuidos en tres especialidades científicas: Física/Química, Biología/Geología y Matemáticas. Debido al gran número de estudiantes del MUFPES de ramas de ciencias que estaban interesados en participar, fue necesario reducir el número de la muestra final para poder garantizar la calidad de las sesiones. Por ello, se escogieron a los sujetos que iban a realizar las prácticas docentes en institutos de la ciudad de Badajoz, para evitar que tuvieran que desplazarse y poder faltar a alguna de las sesiones.

Para fomentar la reflexión, se decidió cada grupo debería estar formado por tres personas. Al existir un mayor número de participantes de la especialidad de Biología/Geología, se crearon dos grupos para esta especialidad. Esta circunstancia se debía a que la mayoría de los estudiantes matriculados en el MUFPES provenían de 
titulaciones relacionadas con la Biología.

La distribución por género, edad y carrera universitaria se encuentra en la Tabla 1. Para garantizar el anonimato de los participantes, se asignó un número a cada sujeto. Participaron 7 mujeres y 5 hombres, con edades comprendidas entre los 23 y 29 años.

Tabla 1. Distribución de la muestra del PSAPD por género, edad y licenciatura

\begin{tabular}{|c|c|c|c|c|}
\hline \multicolumn{2}{|l|}{ Participantes } & Género & Edad & Licenciatura \\
\hline \multirow{6}{*}{ Biología/Geología } & Sujeto 1 & Hombre & 29 & Biología \\
\hline & Sujeto 2 & Hombre & 29 & Biología \\
\hline & Sujeto 3 & Mujer & 28 & Biología \\
\hline & Sujeto 4 & Mujer & 27 & Biología \\
\hline & Sujeto 5 & Hombre & 27 & Ciencia y Tecnología de los Alimentos \\
\hline & Sujeto 6 & Mujer & 24 & Biología \\
\hline \multirow{3}{*}{ Física/Química } & Sujeto 7 & Hombre & 28 & Física \\
\hline & Sujeto 8 & Mujer & 24 & Química \\
\hline & Sujeto 9 & Mujer & 23 & Química \\
\hline \multirow{3}{*}{ Matemáticas } & Sujeto 10 & Hombre & 24 & Matemáticas \\
\hline & Sujeto 11 & Mujer & 23 & Matemáticas \\
\hline & Sujeto 12 & Mujer & 23 & Matemáticas \\
\hline
\end{tabular}

\section{Procedimientos de recogida y análisis de datos}

Antes de comenzar el PSAPD, se formó el equipo de trabajo interdisciplinar que diseñaría e implementaría el programa, compuesto por profesionales de diferentes disciplinas: Didáctica de las Ciencias Experimentales, Psicología y Psicopedagogía. Posteriormente, y tras la formulación de los objetivos, se diseñaron y planificaron las actividades a realizar en tres momentos: antes, durante y después de las prácticas docentes que realizan los futuros profesores de Secundaria en los Institutos.

Los futuros profesores de Secundaria fueron informados sobre el PSAPD en una clase lectiva del MUFPES. Se discutieron resultados obtenidos en otros estudios sobre emociones y creencias de autoeficacia docente (Brígido, Borrachero, Bermejo y Mellado, 2013), para que fueran conscientes de la importancia del dominio afectivo en la enseñanza y aprendizaje de las ciencias y las matemáticas. Se les habló del equipo multidisciplinar que lo iba a desarrollar, de las sesiones que se iban a realizar y de lo que se esperaba conseguir con él. Seguidamente, se compartió una lista donde los sujetos interesados debían apuntarse si querían participar. Siempre incidiendo en que el PSAPD era totalmente voluntario, que no era evaluable para el MUFPES y que se desarrollaría en horario extraescolar.

Una vez elegida la muestra, se realizó una entrevista individual con los participantes. Esta actividad daría inicio al programa que, después de varias sesiones más, culminaría con otra entrevista individual al finalizar las prácticas docentes. Las diferentes sesiones presenciales se realizaron en seminarios de la Facultad de Educación adaptados a las necesidades del programa. Aproximadamente, se llevó a cabo una sesión cada 15 días, con una duración máxima de 2 o 3 horas, desde febrero a junio de 2011. Siempre hubo plena asistencia de los participantes.

En todo momento se tenía presente que el fin del programa de intervención se basaba 
en mejorar la calidad de la enseñanza y el aprendizaje de las ciencias, mediante la representación de situaciones problemáticas en la docencia y su posterior reflexión, utilizando estrategias autorreguladoras, y procurando un cambio cognitivo a través del fomento de emociones positivas y de altas creencias de autoeficacia docente. En la Figura 1 se puede observar un esquema sobre la finalidad del PSAPD.

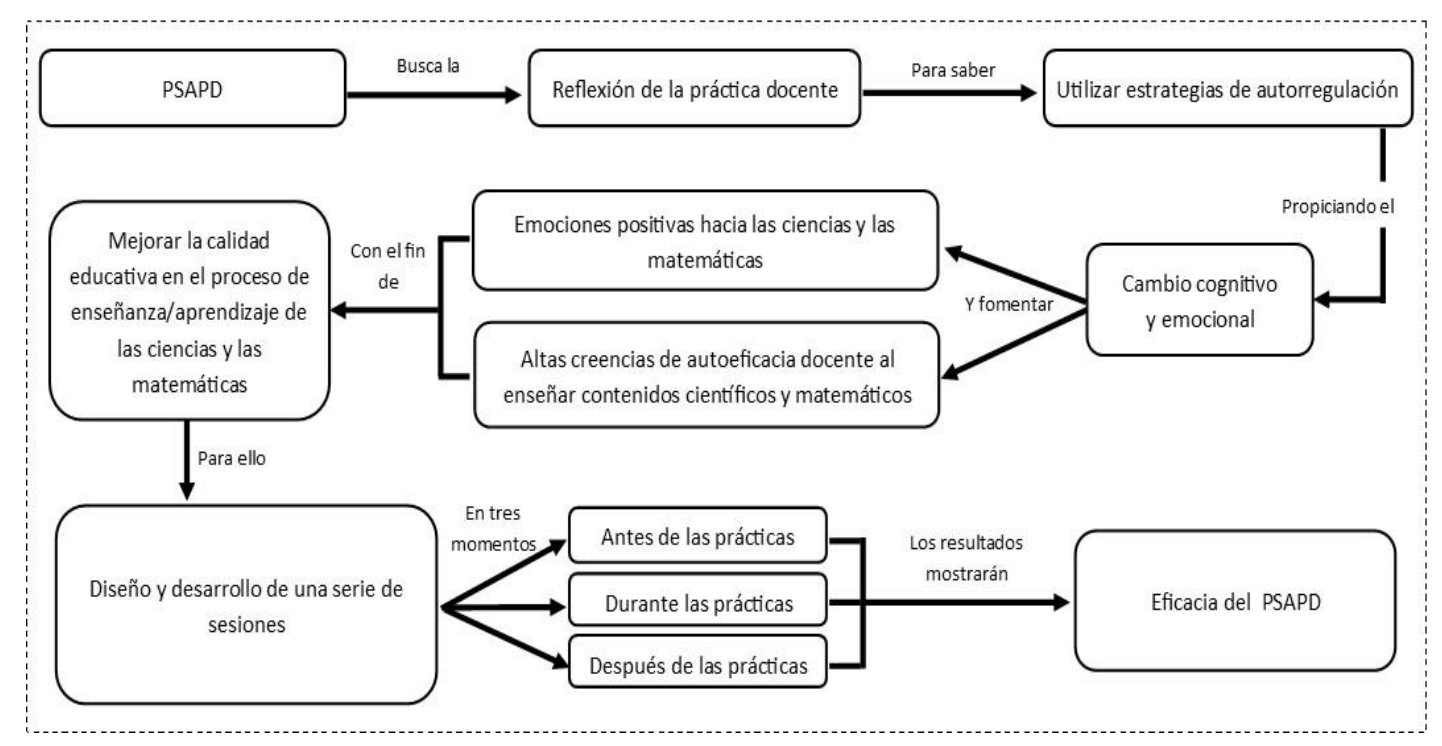

Figura 1. Resumen de la finalidad del PSAPD

\section{Instrumentos}

Se diseñaron una serie de instrumentos y sesiones prácticas con el fin de recabar la información necesaria y dotar al futuro profesor de estrategias y recursos que pudieran utilizar en el proceso de enseñanza/aprendizaje en sus prácticas docentes (Figura 2).

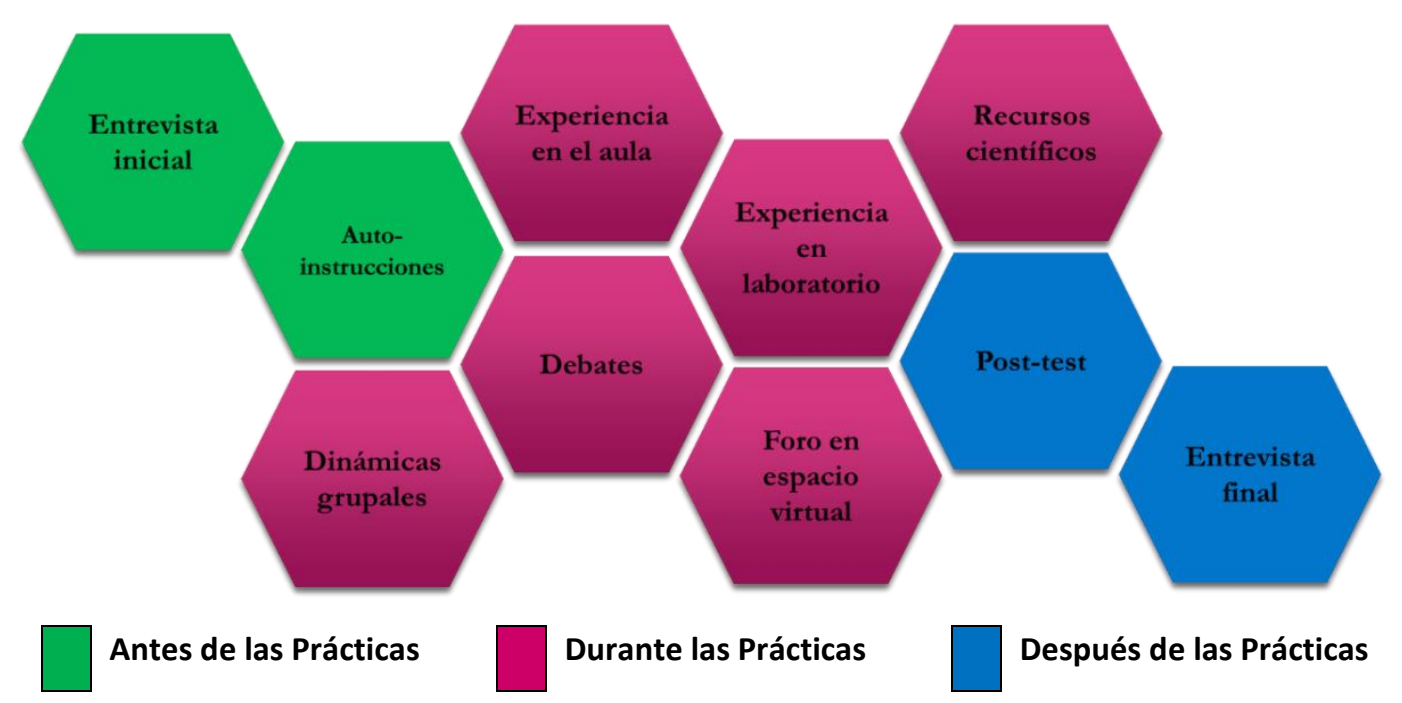

Figura 2. Resumen de los instrumentos y sesiones del PSAPD

En los sucesivos sub-apartados, se desarrollarán brevemente cada una de las actividades diseñadas. 


\section{Entrevista inicial}

La entrevista es una de las principales técnicas de investigación cualitativa en educación definida como la técnica de investigación adecuada para que los investigadores establezcan relaciones con los entrevistados, facilitando un clima agradable de confianza y comunicación, donde entrevistado y entrevistador exploran juntos el significado de los sucesos que tienen lugar.

Atendiendo a los tipos de entrevistas (estructuradas, semiestructuradas y abiertas) referidas al grado en que las preguntas realizadas por el entrevistador han sido previamente diseñadas (Wengraf, 2001), se eligió la entrevista semiestructurada. El diseño de la entrevista semiestructurada permitió contar con un número de preguntas abiertas previamente preparadas, que hicieron posible la improvisación y el tratamiento de distintos temas sugeridos por las propias respuestas. En la Tabla 2 se expone el guion de la entrevista inicial. Dicha entrevista, se realizó de manera individual, antes de comenzar el periodo de prácticas docente. Se contaba con el consentimiento de la grabación en audio de la conversación.

Tabla 2. Guion de preguntas realizadas a los participantes del PSAPD en la entrevista inicial

\begin{tabular}{|c|c|}
\hline Categoría & Preguntas \\
\hline \multirow{6}{*}{$\begin{array}{l}\text { Datos } \\
\text { personales y } \\
\text { académicos }\end{array}$} & ¿Cuántos años tienes? \\
\hline & ¿Eres licenciado/a en...? \\
\hline & ¿Ahora qué has terminado tu carrera, te ha gustado? \\
\hline & ¿Por qué decidiste realizar el MUFPES? \\
\hline & ¿Sabes dónde vas a realizar las prácticas docentes? \\
\hline & ¿Qué curso? ¿Conoces a tu tutor/a? \\
\hline \multirow{8}{*}{ Formación } & ¿Dónde cursaste Educación Primaria? \\
\hline & ¿Qué recuerdas de primaria de las asignaturas de ciencias? ¿Te gustaban? \\
\hline & ¿A diferencia de tus compañeros/as, o a todos/as os gustaban en general? \\
\hline & ¿Y en Educación Secundaria y Bachillerato? \\
\hline & ¿Y en el resto de asignatura de letras y ciencias sociales? \\
\hline & ¿Al llegar a la Universidad tenías claro que querías hacer... (licenciatura)? \\
\hline & ¿Notaste el cambio de Secundaria a la Universidad? \\
\hline & ¿Qué opinas de este Máster? \\
\hline \multirow{4}{*}{$\begin{array}{l}\text { Recuerdo } \\
\text { escolar }\end{array}$} & ¿Recuerdas algún profesor/a que te haya marcado para bien? \\
\hline & ¿Te gustaba la metodología que utilizaba? \\
\hline & ¿Realizaba actividades prácticas, experiencias, ...? \\
\hline & ¿Y alguno que no te gustara? ¿Por qué? \\
\hline \multirow{2}{*}{$\begin{array}{l}\text { Actitud hacia la } \\
\text { ciencia }\end{array}$} & ¿Qué utilidad le das a las ciencias en la vida cotidiana? \\
\hline & $\begin{array}{l}\text { ¿Consideras que tu actitud hacia las ciencias ha cambiado con el paso de tu } \\
\text { escolaridad? }\end{array}$ \\
\hline \multirow{3}{*}{$\begin{array}{l}\text { Autoeficacia } \\
\text { docente }\end{array}$} & ¿Te sientes capacitado/a para realizar las prácticas? \\
\hline & ¿Qué metodología te gustaría utilizar en las prácticas? \\
\hline & ¿Utilizarías actividades prácticas? \\
\hline \multirow{2}{*}{ Autorregulación } & ¿Cómo reaccionarías ante una situación extraña en el aula? \\
\hline & ¿Cuándo te pones nervioso/a, se te nota? \\
\hline \multirow{2}{*}{$\begin{array}{l}\text { Emociones hacia } \\
\text { las prácticas }\end{array}$} & ¿Cómo te sientes ante las prácticas? \\
\hline & $\begin{array}{l}\text { Dime la primera emoción que se te venga a la cabeza ante las inminentes } \\
\text { prácticas }\end{array}$ \\
\hline Sobre el PSAPD & ¿Qué esperas de este programa? \\
\hline
\end{tabular}

Una vez realizadas las entrevistas individuales a todos los participantes del programa, se 
procedió a la transcripción de las entrevistas. Aproximadamente, cada entrevista tuvo una duración de 30 o 45 minutos. Asimismo, se realizó un análisis de contenidos, codificando las unidades de información y subrayando aquellas conversaciones que parecían más significativas en el grupo.

\section{Auto-instrucciones}

El entrenamiento en auto-instrucciones es una técnica de modificación de la conducta en la que se modifican las autoverbalizaciones (pensamientos o verbalizaciones internas) que un individuo realiza frente a cualquier problema, sustituyéndolas por otras que son más útiles para afrontar dicho problema. La teoría cognitiva de Beck sostiene que los sentimientos negativos son consecuencia de los pensamientos automáticos negativos o valoraciones poco realistas de los acontecimientos (Dobson y Franche, 1995).

El entrenamiento se puede realizar de dos formas: preventiva (antes de que el diálogo interno negativo aparezca) o paliativa (una vez que ya ha aparecido). Los pasos a seguir son los siguientes:

- el diálogo interno y se generará solo ante la misma situación o parecida. Realizar un "repaso" mental e identificar las autoverbalizaciones que nos hacemos ante situaciones que nos provocan emociones negativas provocadas por la falta de control y de estrategias para enfrentarlo.

- Confeccionar una lista de frases positivas que nos podemos decir a nosotros mismos para intentar mejorar la situación negativa.

- Rellenar un cuadro con los siguientes apartados: situación desencadenante de emociones negativas, autoinstrucciones antes, durante y después de la situación conflictiva.

- Realizar, de forma real, las autoverbalizaciones cuando nos encontremos ante la situación desencadenante de emociones negativas.

- Después del enfrentamiento a la situación problemática, es conveniente reforzar la conducta con verbalizaciones de auto-recompensa o auto-refuerzo por el afrontamiento realizado, con independencia del resultado obtenido ya que se ha seguido el proceso de entrenamiento. Ej.: "Lo he conseguido" o "por lo menos lo he intentado".

- Repetir los pasos anteriores hasta que la autoinstrucción se vuelva automatizada, es decir, hasta que llegue un punto en que no aparecerá la autoverbalización negativa porque la autoinstrucción se ha impuesto de forma inconsciente. El mecanismo ya está establecido, hemos cambiado

Resulta interesante esta práctica para que los futuros profesores modifiquen las autoverbalizaciones negativas en la enseñanza de las ciencias y las sustituyen por otras más positivas, y más en el momento que comenzarán sus primeras experiencias docentes. Asimismo, esta técnica puede ser trasmitida a sus alumnos para que la utilicen en el aprendizaje de los contenidos científicos, de otras materias o en otros aspectos de su vida cotidiana.

\section{Dinámica grupal}

Consiste en la utilización de una dinámica de grupo de role playing o juego de roles. Esta técnica se basa en interpretar o dramatizar, donde un grupo de personas representan una situación o un caso concreto de la vida real, actuando según el papel que se les ha asignado y de tal forma que parezca real. No se utiliza un guion, sino que los propios 
personajes intervendrán cuando lo consideren oportuno, improvisando en todo momento (García-López, 2009). El role playing en educación es una forma de aprendizaje en la que los alumnos representan papeles asignados con antelación. Esto requiere una participación activa por parte de todos los miembros. Si se crea un ambiente relajado, esta actividad ofrece la oportunidad de asumir papeles o practicar habilidades que de otra manera no las ejercitarían por vergüenza o miedo a las consecuencias en la vida real. El profesor debe evitar intervenir durante su desarrollo, limitándose a observar y escuchar.

La actividad sirve para conocer las actitudes que tenemos ante determinadas situaciones y cómo influyen en nuestra labor y en nuestra vida, para analizar también determinadas tensiones que surgen en el proceso grupal y para potenciar la capacidad de empatía entre los sujetos participantes respecto a diferentes situaciones que nos parecen interesantes. Además, permite a los sujetos experimentar nuevos comportamientos en un clima de riesgo limitado, pues no se trata de una situación real. Los participantes se dan cuenta de lo que hacen, como lo hacen y de las consecuencias de sus comportamientos. Ellos mismos identifican diferentes formas de reaccionar y su grado de eficacia. Para nuestro programa, la finalidad de la realización de esta dinámica se basa en varios objetivos que desarrollamos en los siguientes puntos:

- Fomentar la comunicación entre los miembros del grupo y aumentar, a su vez, la participación.

- Mostrar posibles situaciones problemáticas que pueden surgir en el aula de Secundaria, llevándolas incluso al extremo.

- Analizar las emociones que había experimentado el actor principal.

- Realizar una crítica de las decisiones que se habían tomado y de las estrategias que se habían seguido.

- Llegar a un consenso de cómo actuar de forma más adecuada.

Debate

El debate se define, dentro del proceso de aprendizaje, como la confrontación de argumentos sólidos con el fin de conocer problemas y superarlos. Implica el desarrollo y el fomento de capacidades para asumir ideas y visiones propias de la realidad, de disentir y de ser tolerantes con los demás (Yanes, 2007).

Esta técnica se desarrollará en la tercera sesión, paralelamente al periodo de prácticas. Se realizarán debates sobre situaciones hipotéticas que pueden encontrarse durante las prácticas. Por ejemplo el caso siguiente: "Samuel, licenciado en Matemáticas, ha comenzado sus prácticas en un instituto localizado en un barrio conflictivo de la ciudad. Su tutora es profesora de Matemáticas de dos cursos de 4이 de la ESO. En uno de los grupos, hay dos alumnas que no quieren aprender. Cuando la profesora explica, ellas no atienden. No hacen los ejercicios, ni en clase ni en sus casas. Y en los exámenes sólo ponen el nombre y los entregan en blanco. La tutora le ha dicho a Samuel que las deje de lado como hace ella, que no pierda el tiempo en hacerlas aprender porque ya están perdidas. Samuel ha preguntado al resto de los profesores y esta situación solamente ocurre en el aula de Matemáticas con esta profesora".

La clase será dividida en dos grupos de seis participantes. Uno de ellos deberá defender la postura de la profesora obligando a Samuel a dejar a estas alumnas de lado. El otro grupo deberá defender la idea de que todos los alumnos merecen ser enseñados aunque conlleve más esfuerzo, por lo que Samuel debería involucrarse especialmente con esas dos alumnas. 


\section{Experiencia en el laboratorio}

Para comprobar cómo se desenvuelven y se sienten los futuros profesores de secundaria ante una actividad práctica de laboratorio, se diseñó una experiencia de laboratorio (González, Mellado y Ruiz, 2005). En ella, los participantes dejarán su rol de futuros profesores para ser otra vez estudiantes de ciencias. La actividad consiste en calcular el periodo de oscilación de un péndulo simple.

La elección de esta actividad se fundamenta en la importancia que el péndulo ha tenido en el desarrollo de la ciencia y de la cultura de occidente (Matthews, Gauld y Stinner, 2005), y por las posibilidades formativas en la enseñanza de las ciencias, reconocidas desde las experiencias de Inhelder y Piaget (1958), por ser una actividad accesible que incluye los diferentes procesos de la metodología científica (Zachos, 2004) y porque en ella pueden fomentarse tanto los factores cognitivos como afectivos (Matthews, 2000).

El cálculo de las diferentes variables que influyen en el periodo de oscilación del péndulo simple, se plantea como actividad de intervención emocional y cognitiva que combina las actividades prácticas de laboratorio y la resolución de problemas, dos actividades tradicionalmente separadas, pero que juntas constituyen un enorme potencial para la educación (Gil et al., 1999).

\section{Experiencia en el aula}

La última sesión grupal se planifica como una actividad de seguimiento y autorregulación. Según Cañal, Travé y Pozuelos (2011), este tipo de actividades sirven para que la persona, en solitario o en equipo, analice y valore durante el desarrollo de un trabajo, algún aspecto de lo realizado, ya sea el plan de trabajo, las actuaciones, los procedimientos e instrumentos utilizados, las dificultades que ha encontrado, los logros que ha obtenido, los fracasos, etc., con la intención de introducir los cambios o mejoras que se vean necesarios en cada momento. El fin de esta sesión se basaba en que cada uno de los participantes cuente abiertamente si considera que habían cambiado sus actitudes y sus emociones en el desarrollo de las prácticas y que estrategias estaban utilizando para ello.

\section{Foro virtual}

En el desarrollo del PSAPD se cuenta con un espacio en la plataforma Moodle del campus virtual, diseñado para crear ambientes de aprendizajes personalizados que puedan utilizar educadores, administradores y estudiantes, proporcionando un conjunto de herramientas centradas en el estudiante y en ambientes de aprendizaje colaborativo. Es una interfaz sencilla de usar y gratuita.

Una de las utilidades para este espacio será el uso de la herramienta de foro. El foro virtual es un espacio de comunicación formado por ventanas de diálogo en los que se van incluyendo mensajes que pueden ir clasificados temáticamente. En este sentido, los usuarios pueden realizar nuevas aportaciones, aclarar otras, contestar a otros participantes, etc., de una forma asincrónica, haciendo posible que las aportaciones de los usuarios permanezcan en el tiempo a disposición de los demás participantes. Es una herramienta que se puede utilizar y consultar en cualquier momento y desde cualquier lugar que posea conexión a internet.

Desde el punto de vista educativo, los foros permiten el intercambio de información, el debate, el diálogo y la comunicación, la socialización y el aprendizaje colaborativo. Para nosotros ha sido una herramienta importante, pues a través de él, hemos podido comunicarnos con los futuros profesores y ellos también lo han utilizado para 
comunicarse entre sí y para comentar sus dudas y experiencias.

\section{Recursos científicos}

Ya que muchos de los participantes manifestaban lagunas en el ámbito didáctico y psicológico, durante todo el programa se puso a su disposición una serie de libros de textos de Secundaria y direcciones web de diferentes revistas y libros relacionados con la enseñanza de las ciencias. Asimismo, se ofreció la disponibilidad de los diferentes miembros del Departamento de Didáctica de las Ciencias Experimentales y Matemáticas (UEx) por si en algún momento necesitaban de una mayor orientación.

\section{Post-test}

Las emociones que experimentaban los futuros docentes en la enseñanza de contenidos científicos fueron recogidas en dos momentos: antes de comenzar las prácticas y después de terminar las prácticas. Para ello, se utilizó un cuestionario que presentaba un apartado para introducir una clave (dibujo, palabra, cifra, etc.) con el fin de poder recuperarlo y comparar que emociones experimentaban antes de comenzar sus prácticas y que emociones habían experimentado al terminar las prácticas.

En el cuestionario se presentaban un total de 16 emociones ( 8 emociones positivas y 8 emociones negativas; Tabla 3) donde el participante debía señalar si creía que, ante la enseñanza de contenidos científicos relacionados con su especialidad, experimentaba las emociones propuestas. Dichas emociones fueron escogidas a partir de las clasificaciones realizadas por Damasio (2005), Goleman (1996) y Fernández-Abascal, Martín y Domínguez (2001).

Tabla 3. Clasificación de emociones comunes de los cuestionarios del MUFPES

\begin{tabular}{|c|c|c|c|}
\hline 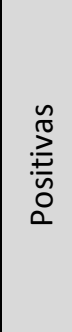 & $\begin{array}{l}\text { Alegría } \\
\text { Confianza } \\
\text { Diversión } \\
\text { Orgullo } \\
\text { Placer } \\
\text { Satisfacción } \\
\text { Simpatía } \\
\text { Tranquilidad }\end{array}$ & 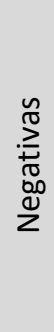 & $\begin{array}{l}\text { Aburrimiento } \\
\text { Ansiedad } \\
\text { Desesperación } \\
\text { Irritabilidad } \\
\text { Nerviosismo } \\
\text { Odio } \\
\text { Pesimismo } \\
\text { Preocupación }\end{array}$ \\
\hline
\end{tabular}

\section{Entrevista final}

La entrevista final semiestructurada se realizó con la intención de conocer cómo cambiaron sus emociones, su autorregulación y sus creencias de autoeficacia a lo largo de las prácticas y cómo ha podido influir en estos cambios el PSAPD que se realizó. Para ello, se confeccionaron las siguientes preguntas (Tabla 4).

Tabla 4. Guion de preguntas realizadas a los participantes del PSAPD en la entrevista final

\begin{tabular}{|l|l|}
\hline \multicolumn{1}{|c|}{ Categoría } & \multicolumn{1}{c|}{ Preguntas } \\
\hline \multirow{2}{*}{$\begin{array}{l}\text { Autoeficacia } \\
\text { docente }\end{array}$} & Ahora, ¿te sientes capacitado/a para ejercer la docencia? \\
\cline { 2 - 2 } & ¿Qué metodología has utilizado en las prácticas? \\
\cline { 2 - 2 } & ¿Consideras que tus alumnos han aprendido con tu enseñanza? \\
\hline \multirow{2}{*}{ Autorregulación } & ¿Cómo has reaccionado ante una situación extraña en el aula? \\
\cline { 2 - 2 } & ¿Qué hacías cuándo te ponías nervioso/a? \\
\hline Emociones hacia & ¿Cómo te sientes ahora que has terminado las prácticas? \\
\cline { 2 - 2 } las prácticas & Dime la primera emoción que se te venga a la cabeza \\
\hline Sobre el PSAPD & ¿Consideras que el programa te ha ayudado? ¿Cómo? \\
\hline
\end{tabular}




\section{Resultados}

Los resultados obtenidos se presentan en función de los entrevistas realizadas: antes y después de realizar el PSAPD. Seguidamente, se realizará una comparación de las emociones experimentadas en ambos momentos. Dado que en las tres especialidades no había el mismo número de sujetos, los resultados se expresan en porcentajes.

\section{Resultados de la entrevista inicial.}

La realización de la entrevista antes de comenzar las prácticas docentes y el programa, puso de manifiesto la baja autoeficacia docente que presentaban los profesores en formación, donde comenzaban a aparecer los miedos y las dudas. Estas son algunas de las afirmaciones que realizaron:

“¿Si me siento preparado para dar una clase? Eso se verá con el tiempo. En seis meses me puedo llegar a sentir instruido, capacitado, pero por mucho conocimientos que tenga... a mi tantas cosas... ya no me acuerdo. Y además la geología, yo huyo de la geología..." (Sujeto 1).

“Supongo que tendré momentos en blanco y que querré salir corriendo"(Sujeto 7).

"Me da miedo. En cuanto a conocimientos sí, en cuanto como tratar a los niños y saber cómo manejarlos y tal no. Pues hasta que no llegue el momento no sé cómo va a salir. Me da miedo tratar con adolescentes, en tercero de la ESO. Me han enseñado los cambios que tienen los adolescentes en su cuerpo, no como tratarlos" (Sujeto 8).

Las preguntas relacionadas con la autorregulación dejaron patentes que no sabrían cómo reaccionar ante posibles situaciones extrañas que se les presentarán en el aula.

“Me quedaría quieto, me pondría más serio, sudaría,... no sé. No sería capaz de disimularlo. Creo que no podría continuar" (Sujeto 1).

“No sé cómo reaccionaría. Yo suele ser muy nerviosa, así que enseguida me subirían los colores e intentaría cambiar de tema. No sé, espero que no me pase. Yo tengo más conocimientos que ellos, pero quizás no sabría cómo explicarme" (Sujeto 6).

“Tartamudearía, sudaría, e intentaría salir del paso. iQué mal rato pasaría!” (Sujeto 7).

“Me pondría colorada y empezaría a hablar muy rápido. De esto que dices tierra trágame. Sí se me notaría bastante" (Sujeto 11).

Algunos tenían ciertas estrategias preparadas, pero afirmaban que no serían capaces de disimular sus nervios:

"Ante una pregunta que no supiera le diría: imuy buena pregunta! Vamos a hacer una cosa, todos los niños de la clase que busquen la respuesta a esto y mañana me la decís y yo os digo cual es la correcta..., así de paso me da tiempo a mí a mirármela también... Creo que esta técnica ya está muy vista, pero si no me funciona no sé qué voy a hacer..." (Sujeto 5).

De forma general, los futuros profesores de Secundaria en estudio experimentaban emociones negativas y positivas a la vez, previas a las prácticas docentes. Las primeras emociones que manifestaron fueron incertidumbre, curiosidad, nerviosismo e ilusión. Se les notaba que estaban expectantes por empezar, aunque tenían sus dudas comprensibles:

\footnotetext{
"Me da miedo. No sé qué me voy a encontrar, cómo van a ser los alumnos... Siento incertidumbre ante lo desconocido, pero a la misma vez ilusión por empezar algo nuevo" (Sujeto 4).

“Quiero que empiecen ya. No sé qué me voy a encontrar, pero quiero hacerlo ya. Tengo
} 
mucha ilusión pero a la vez me encuentro nerviosa" (Sujeto 9).

“Nervios. Además yo soy muy nerviosa, soy hiperactiva. El día antes no duermo, bueno, la semana antes no duermo" (Sujeto 12).

El argumento que nos daban sobre qué era lo que esperaban del programa al que se habían apuntado voluntariamente, coincidía bastante entre todos los entrevistados. Necesitaban más formación, más estrategias para enfrentarse a la docencia y saber tratar a los alumnos. No se sentían respaldados con la formación del Máster y necesitaban más conocimientos didácticos:

"Pues espero un apoyo, algo que no he tenido durante todo el Máster. Si conseguís que regule mis miedos, que sea capaz de tratar al niño y que aprenda, me habréis hecho feliz" (Sujeto 1).

“Espero aprender a manejar bien las situaciones, a saber actuar bien en cada contexto, a ganar confianza en mí misma como docente, a crear un clima de confianza y respeto con los chicos..." (Sujeto 11).

“Espero saber cómo actuar en una clase. Porque yo creo que es lo que menos nos han enseñado y lo más fundamental también para dar una clase, el saber ponerte delante, el cómo tienes que actuar, el si ves que pasa esto que puedes hacer, o que opciones tienes, todo eso que a lo mejor en otras asignaturas no ves" (Sujeto 12).

\section{Resultados de entrevista final}

La entrevista final se realizó con la intención de evaluar el programa de intervención. Ya conocíamos, a través de las sesiones e instrumentos utilizados, que sus emociones habían ido cambiando a lo largo de las prácticas, y que sus creencias de autoeficacia y autoconcepto habían ido aumentado, pero queríamos conocer cómo había podido influir en estos cambios el PSAPD que realizamos.

A continuación, exponemos algunas trascripciones de las entrevistas mantenidas con los participantes, donde ellos, por sí mismos, nos contaban qué pensaban del programa y para qué les había servido. Satisfactoriamente para nosotros, fueron muy positivas:

“...Yo estoy muy agradecida por todo lo que habéis hecho por nosotros. Me habéis ayudado mucho a centrarme, a confiar en mí mismo, a perder mis miedos, a saber actuar ante los chicos y a afrontar las clases de geología que me producían una ansiedad enorme. Además, el trato con mis compañeros ha sido increíble. A algunos de ellos ni siquiera los conocía al ser de otras especialidades y ahora son amigos... En los seminarios de las prácticas es donde más he notado la diferencia, porque mis compañeros del máster estaban como asustados y perdidos, y en el siguiente seminario volvían a estar igual, y yo cada vez me encontraba mejor..." (Sujeto 4).

“Este programa sí me ha servido. Me ha servido para entender mejor la docencia... me habéis dado estrategias y me habéis hecho reflexionar sobre mi propia actitud, cosa que el máster que se supone que te prepara para ser profesor no había hecho. Pero lo mejor de todo es que no lo habéis hecho teóricamente, sino que nosotros mismos, a través de la práctica, lo hemos ido interiorizando. Al principio estaba un poco agobiado por la falta de tiempo pero ahora estoy muy satisfecho de haber acudido. Ha sido una gran experiencia, y además útil" (Sujeto 7).

"Qué pena me da que esto se acabe. ¿Cuándo comience a trabajar puedo acudir a ti? (risas)... Ya en serio, creo que me habéis ayudado muchísimo. Yo de mi licenciatura tengo muchos conocimientos, muchos, pero intentar que otro los aprenda es difícil. Vosotros me habéis enseñado a hacerlo, y más que nada, que si sale mal no hay que venirse abajo, hay que intentar hacerlo mejor y con positividad... Me recuerdo a mí misma cuando hicimos la primera entrevista y estaba muertita de miedo aunque con mucha ilusión por empezar... y 
ahora quiero más... Espero poder seguir utilizando todo lo que me habéis enseñado cuando apruebe las oposiciones..." (Sujeto 11).

\section{Comparación de las emociones experimentadas en pre-test y post-test.}

A continuación, se realiza una comparación de las emociones experimentadas antes y después de realizar el programa de intervención. La Figura 3 muestra las emociones experimentadas por los futuros profesores de la espacialidad de Biología/Geología al impartir contenidos de Biología. Encontramos que el $100 \%$ de los futuros docentes mejoraron sus emociones positivas al terminar el programa, desapareciendo las emociones negativas que experimentaban al comienzo (preocupación, nerviosismo, ansiedad).

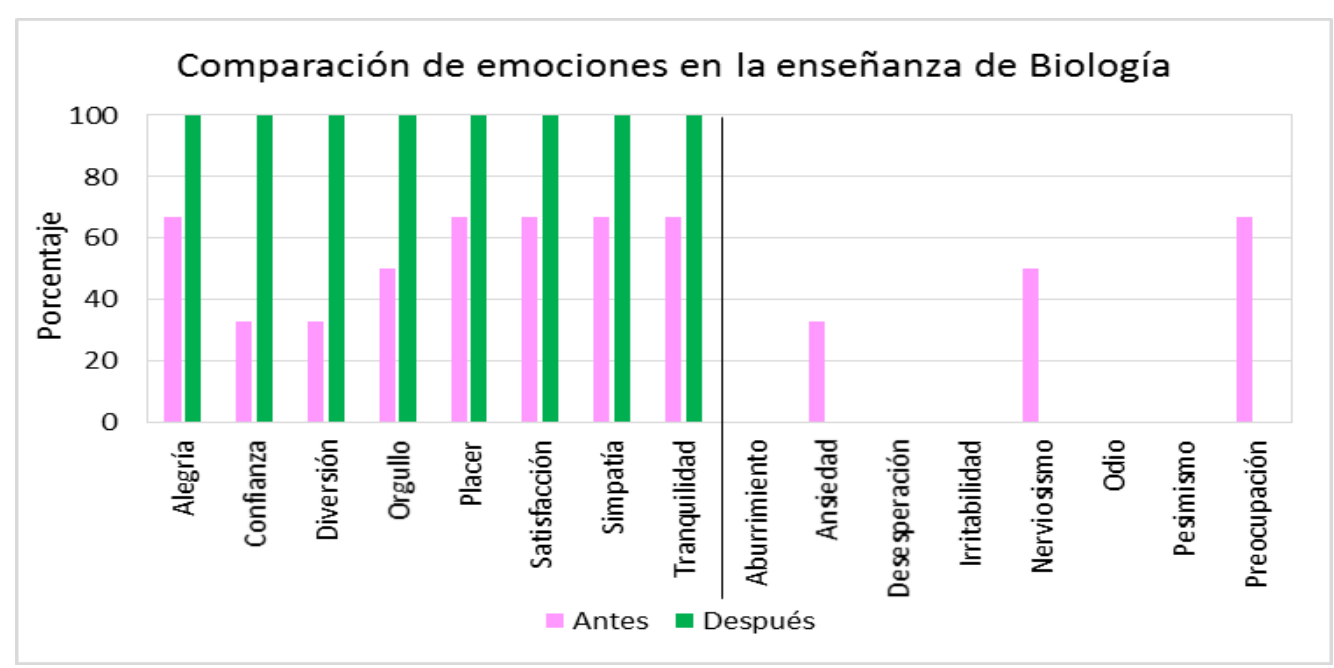

Figura 3. Emociones experimentadas por los futuros profesores de la especialidad de Biología/Geología en la enseñanza de Biología (ESO), antes y después del PSAPD

En la Figura 4 observamos las emociones experimentadas por los futuros profesores de Secundaria de la espacialidad de Biología/Geología al impartir contenidos de Geología. Recordamos que la mayoría de los participantes provenían de titulaciones relacionadas con la Biología. En esta ocasión, vemos que las emociones positivas han subido después de realizar el programa, y las emociones negativas han bajado.

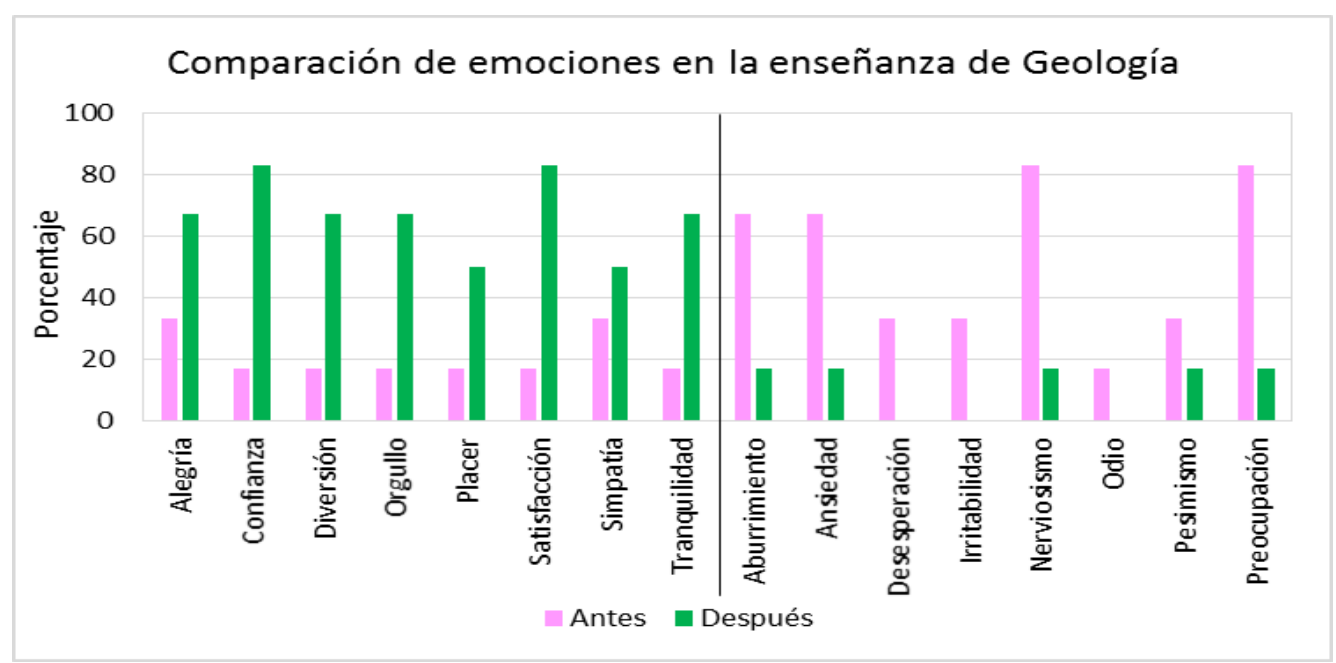

Figura 4. Emociones experimentadas por los futuros profesores de la especialidad de Biología/Geología en la enseñanza de Geología (ESO), antes y después del PSAPD 
La Figura 5 indica las emociones experimentadas por los sujetos participantes en la especialidad de Física/Química, al enseñar contenidos de Física. Encontramos que las emociones negativas como nerviosismo, preocupación, ansiedad y pesimismo desaparecen al terminar el programa. También vemos como las emociones positivas aumentan.

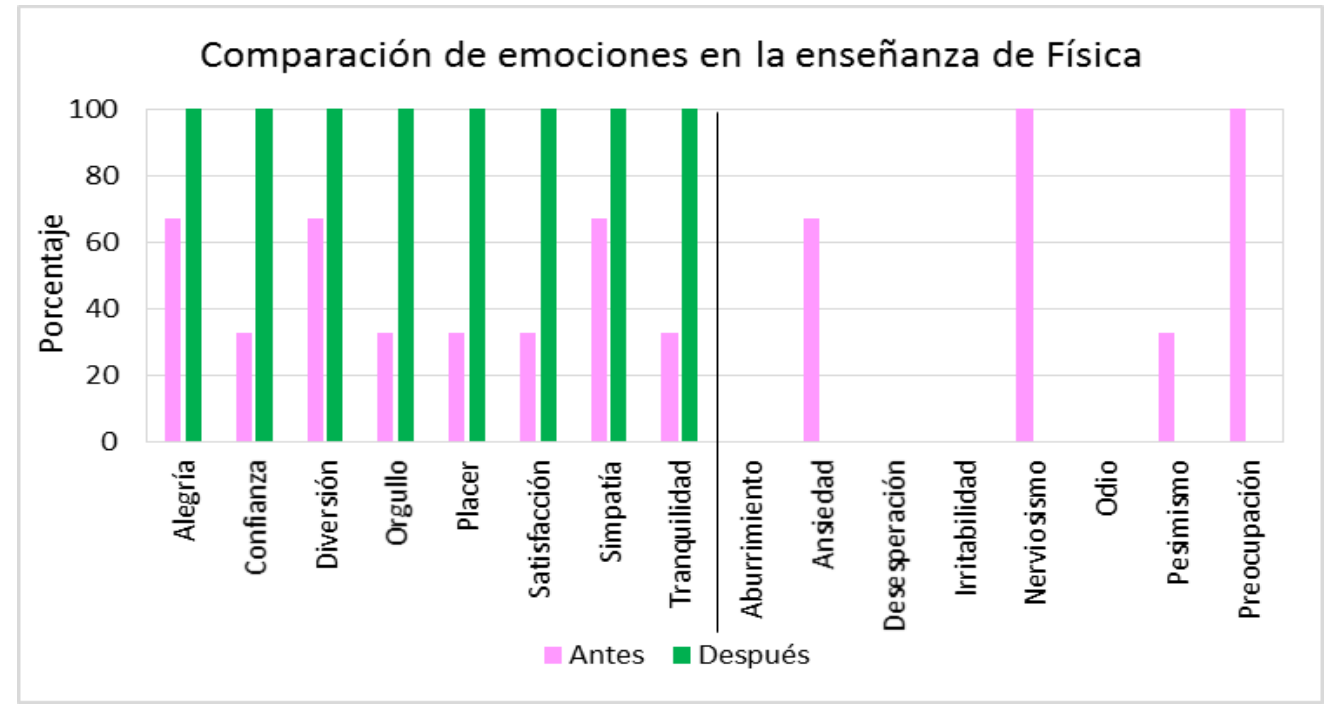

Figura 5. Emociones experimentadas por los futuros profesores de la especialidad de Física/Química en la enseñanza de Física (ESO), antes y después del PSAPD

El gráfico de barras de la Figura 6 muestra las emociones experimentadas por los profesores en formación de la especialidad de Física/Química, al enseñar contenidos de Química. Una vez más, vemos como las emociones positivas aumentan y las emociones negativas desaparecen al terminar el programa de intervención.

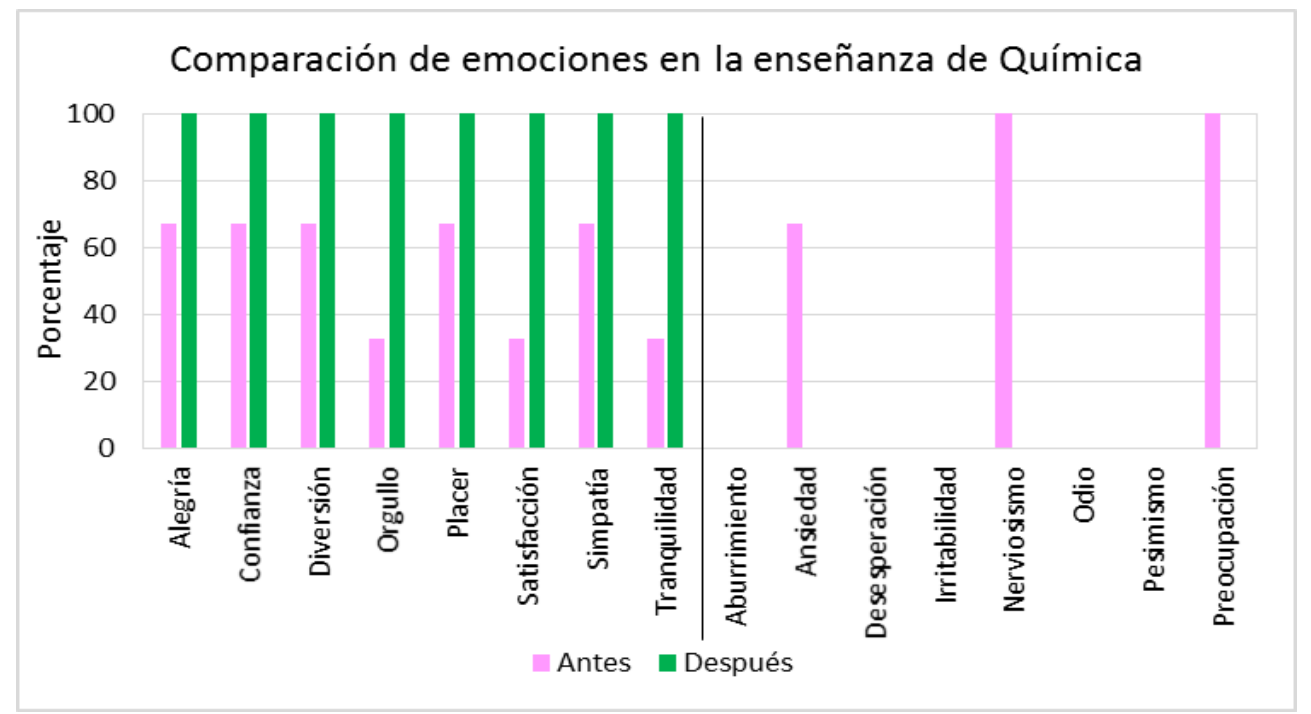

Figura 6. Emociones experimentadas por los futuros profesores de la especialidad de Física/Química en la enseñanza de Química (ESO), antes y después del PSAPD

La Figura 7 muestra las emociones experimentadas por los futuros profesores de la especialidad de Matemáticas, al impartir la materia de Matemáticas en Educación Secundaria. Cabe destacar, que estos sujetos manifestaban sentirse tranquilos y 
confiados antes de comenzar las prácticas, pero también nerviosos y preocupados. Con el paso del programa, todas las emociones positivas aumentaron y las emociones negativas experimentadas desaparecieron.

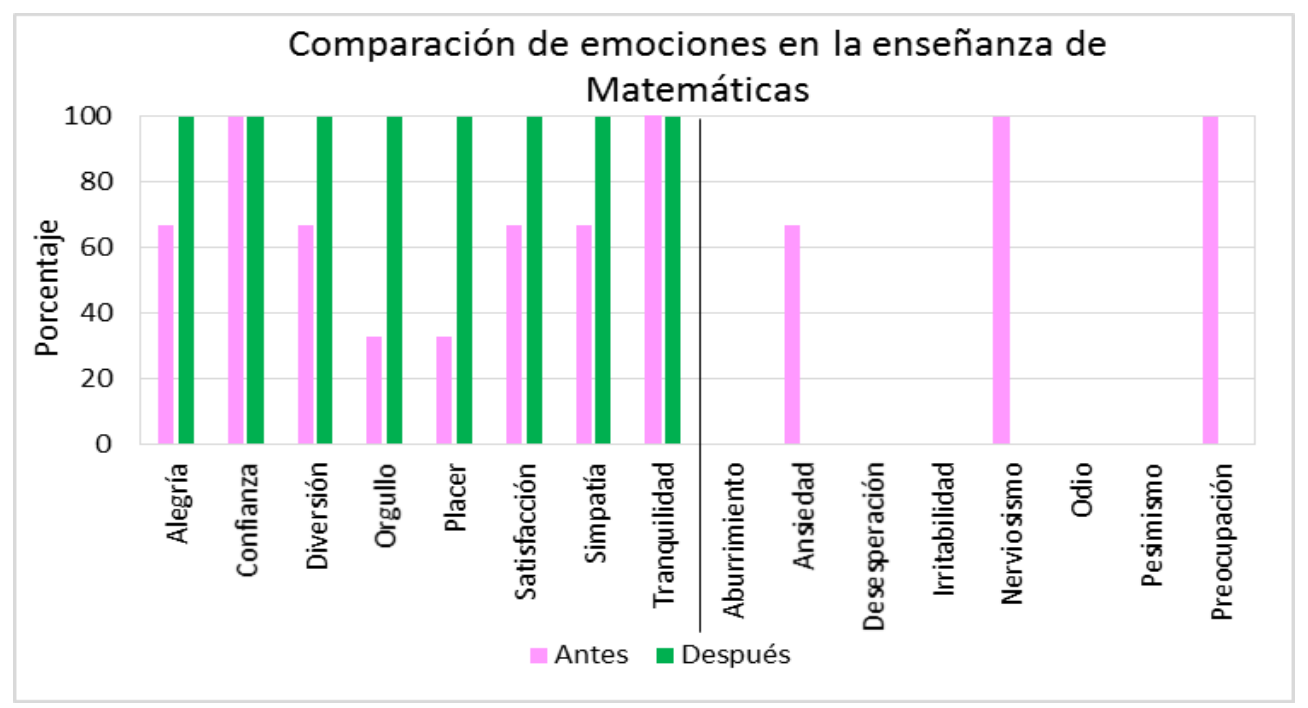

Figura 7. Emociones experimentadas por los futuros profesores de la especialidad de Matemáticas en la enseñanza de Matemáticas (ESO), antes y después del PSAPD

\section{Conclusiones}

La entrevista inicial realizada pone de manifiesto que los futuros docentes presentaban una baja autoeficacia docente, una falta de estrategias para afrontar los problemas en el aula y una importante incapacidad para llegar a autorregularse. Asimismo, el análisis de emociones realizado señalaba que los futuros profesores de ciencias experimentaban un cúmulo de emociones contradictorias, tanto positivas como negativas (alegría, placer, satisfacción, incertidumbre, miedo, nerviosismo, preocupación o ansiedad), antes de comenzar sus prácticas.

La realización del PSAPD propició que los futuros profesores de Educación Secundaria reflexionaran sobre sus emociones hacia las ciencias, como escolares y profesores. Esto les llevó a darse cuenta de que el comienzo de las prácticas docentes les generaba tanto emociones positivas como negativas, y que no se veían capaces de poder solucionar los problemas que pudieran surgir en el aula, pues no poseían los conocimientos pedagógicos, psicológicos, y de didácticas específicas necesarios, ni contaban con estrategias suficientes para actuar con los adolescentes.

Los participantes del programa aprendieron a identificar, valorar y controlar las emociones que les generaba la práctica de enseñanza. Si experimentaban emociones positivas, se sentían más cómodos y alegres para impartir docencia, aumentado su autoeficacia docente. En cambio, si manifestaban emociones negativas utilizaban una serie de estrategias para lograr su autorregulación y cambiarlas por positivas. Además, esto les permitió entender mejor a sus alumnos y crear un clima positivo hacia el aprendizaje de las ciencias.

Se entiende necesario que los futuros profesores de Secundaria valoren las emociones que les genera su práctica de enseñar (Randi, 2004), pues de este modo podrán entender mejor las de sus alumnos, llegando a empatizar con ellos y creando un clima positivo hacia el proceso de enseñanza/aprendizaje de las ciencias. 
La falta de formación en didáctica era el principal causante de las emociones negativas que presentaban los profesores en formación participantes en el programa. La realización del Máster no había satisfecho sus necesidades de aprender contenidos didácticos; incluso muchos de ellos se quejaban de que no habían aprendido ni a realizar una unidad didáctica.

Aunque las emociones negativas, en un principio, tienden a inhabilitar los comportamientos autorreguladores, también pueden llegar a motivar al futuro profesor a cambiar las condiciones que las generan (Pekrun, 1992). Un cierto grado de emoción negativa fomenta la capacidad de encontrar aquello que no acaba de funcionar en el ejercicio de la labor docente. Pero si las emociones negativas se registran en altos niveles, como la ansiedad, el profesor en formación bloqueará toda posibilidad de autorregulación (Hugo, 2008).

A través de las diversas sesiones, los participantes aprendieron a utilizar diferentes estrategias para enfrentarse favorablemente a la enseñanza de contenidos más problemáticos para ellos, fomentando su propia capacidad como docente y repercutiendo también en la capacidad de sus alumnos para aprender estos contenidos. No se puede obviar que, si tanto profesores como estudiantes, no confían en su propia eficacia hacia la enseñanza y el aprendizaje de las ciencias, tratarán de evitar los problemas científicos más complicados, dedicándoles menos tiempo e inhabilitando el diseño y desarrollo de estrategias para superarlos.

En este sentido, Hugo (2008) comenta que una acertada regulación emocional, en los procesos de aprender a enseñar ciencias, es aquella que se da cuando el profesor en formación consigue que sus emociones no le impidan conseguir sus logros docentes, superando los conflictos que puedan aparecer el camino. Esto supone que, para que el futuro docente aprenda a autorregular sus emociones, de las que no siempre es consciente, debe primero llegar a autorregular sus pensamientos.

Los diversos datos obtenidos con la realización del PSAPD y los comentarios que los participantes compartieron tras la finalización del mismo, señalaban que se ha contribuido a la formación inicial de los futuros profesores de Educación Secundaria y que el diseño del programa funcionaba para mejorar las emociones en la enseñanza de las ciencias. Se puede pensar que se han favorecido los procesos de cambio a través de la propia reflexión del futuro profesor de ciencias, dejando de lado las emociones negativas que su falta de conocimientos psicopedagógicos les generaba y adquiriendo un amplio abanico de estrategias para autorregular sus emociones y fomentar su capacidad para enseñar contenidos científicos.

Sin duda, es necesario el desarrollo de programas de intervención en la formación inicial que ayuden a los futuros profesores de ciencias a desarrollar habilidades metacognitivas que contribuyan a la mejora de la calidad educativa. Estas habilidades les permitirán reconocer el origen de sus problemas o dificultades en la labor docente y les facilitarán la autorregulación de los cambios en los factores afectivos dentro del proceso de enseñar contenidos científicos. Sanmartí (2001) apuntaba que en la formación inicial se debe dar la oportunidad a los futuros profesores a que, a través de un proceso metacognitivo de reflexión, sean conscientes de sus creencias y emociones hacia las ciencias en general, la formación científica y sus prácticas de aula, para que puedan llegar a autorregularlas y modificarlas, e ir forjando su modelo didáctico personal. Todos estos futuros profesores de Secundaria llegan a la profesión con un nivel elevado de contenidos específicos de una de las materias, pero carecen de preparación para la 
enseñanza/aprendizaje de estas disciplinas (Mellado et al., 2010).

Finalmente, haría falta un replanteamiento del MUFPES hacia una mayor profesionalización de sus contenidos, una mayor relación entre los módulos teóricos y las prácticas de enseñanza, y unas prácticas no finalistas sino en varias fases integradas con los módulos teóricos (García-Barros, 2016; Pontes, Poyato y Oliva, 2015).

\section{Agradecimientos}

Este trabajo ha sido financiado por los proyectos de investigación EDU2012-34140 y EDU2016-77007-R del Ministerio de Economía y Competitividad, la Junta de Extremadura y los fondos FEDER.

\section{Referencias bibliográficas}

Alsup, J. (2005). Teacher identity discourses: Negotiating personal and professional spaces. Nueva Jersey: Lawrence Erlbaum Associates.

Bañas, C., López, A., Mellado, V. y Ruiz, C. (2009). Metacognition and professional development of secondary education science teachers: A case study. En C.B. Larson (Ed.), Metacognition: New Research Developments (pp.203-222). Nueva York: Nova Science Publishers.

Bisquerra, R. y Pérez, N. (2007). Las competencias emocionales. Educación XXI, 10, 61-82

Blanco, L. J., Guerrero, E., Caballero, A., Brígido, M. y Mellado, V. (2010). The affective dimensions of learning and teaching and teaching mathematics and science. En M.P. Caltone (Ed.), Handbook of Lifelong Learning Developments (pp.265-287). Nueva York: Nova Science Publishers.

Bonil, J. y Márquez, C. (2011). ¿Qué experiencias manifiestan los futuros maestros sobre las clases de ciencias? Implicaciones para su formación. Revista de Educación, 354, 447-472.

Borrachero, A. B. y Brígido, M. (2011). Las emociones de los futuros profesores de Secundaria sobre el aprendizaje de las ciencias según el campo de procedencia. International Journal of Developmental and Educational Psychology. INFAD Revista de Psicología, 1(2), 99-106.

Borrachero, A. B., Brígido, M., Mellado, L., Costillo, E. y Mellado, V. (2014). Emotions in prospective secondary teachers when teaching science content, distinguishing by gender. Research in Science \& Technological Education, 32(2), 182-215. DOI: https://dx.doi.org/10.1080/02635143.2014.909800

Brígido, M. (2014). Programa metacognitivo de intervención emocional en la enseñanza de las ciencias experimentales para maestros de Primaria en formación inicial. Tesis Doctoral. Facultad de Educación, Badajoz: Universidad de Extremadura.

Brígido, M., Bermejo, M. L., Conde, M. C., Borrachero, A. B. y Mellado, V. (2010). Estudio longitudinal de las emociones en ciencias de estudiantes de maestro. Revista Galego-Portuguesa de Psicoloxía e Educación, 18(2), 161-179.

Brígido, M., Borrachero, A. B., Bermejo, M. L. y Dávila, M. A. (2014). Programa de intervención para la mejora de las creencias de autoeficacia en las clases de ciencias. International Journal of Developmental and Educational Psychology. INFAD Revista de Psicología, 5(1), 73-80. 
Brígido, M., Borrachero, A. B., Bermejo, M. L. y Mellado, V. (2013). Prospective primary teachers' self-efficacy and emotions in science teaching. European Journal of Teacher Education, 36(2), 200-217. DOI: https://dx. doi.org/10.1080/ 02619768.2012 .686993

Cañal, P., Travé, G. y Pozuelos, F.J. (2011). Análisis de obstáculos y dificultades de profesores y estudiantes en la utilización de enfoques de investigación escolar. Investigación en la Escuela, 73, 5-26.

Copello, M. y Sanmartí, N. (2001). Fundamentos de un modelo de formación permanente del profesorado de ciencias centrado en la reflexión dialógica sobre las concepciones y las prácticas. Enseñanza de las Ciencias, 19(2), 269-283.

Damasio, A. (2005). En busca de Spinoza. Neurobiología de la emoción y los sentimientos. Barcelona: Crítica.

De Puelles, M. (2003). Las políticas del profesorado en España. En M. C. Benso y M. C. Pereira (Eds.), El profesorado de Enseñanza Secundaria. Retos ante el Nuevo Milenio (pp.17-37). Ourense: Universidad de Vigo.

Delval, J. (2002). Cómo hay que hacer una reforma educativa. Cuadernos de Pedagogía, 313, 86-90.

Désaultes, J., Larochelle, M., Gagné, B y Ruel, F. (1993). La formation à l'enseignement des sciences: le virage épistémologique. Didaskalia, 1, 49-67.

Dobson, K. S. y Franche, R. L. (1995). La práctica de la terapia cognitiva. En V.E. Caballo (Ed.), Manual de técnicas de terapia y modificación de conducta (pp.493-526). Madrid: Siglo XXI.

Efklides, A. (2009). The new look in metacognition: From individual to social, from cognitive to affective. En B. Clayton (Ed.), Metacognition: New Research Developments (pp.137-151). Nueva York: Nova Science Publishers.

Evans, H. y Fisher, D. L. (2000). Cultural differences in students' perceptions of science teachers' interpersonal behavior. Australian Science Teachers Journal, 46(2), 9-18.

Fernández-Abascal, E., Martín, M. y Domínguez, J. (2001). Procesos psicológicos. Madrid: Ediciones Pirámide.

Fritz, J. J., Miller-Heyl, J., Kreutzer, J. C. y Macphee, D. (1995). Fostering teacher efficacy through staff development and classroom activities. The Journal of Educational Research, 88, 200-208.

Furió, C. y Guisasola, J. (1998). Construcción del concepto de potencial eléctrico mediante el aprendizaje por investigación. Revista de Enseñanza de la Física, $11(1), 25-37$

García, M. y Orozco, L. (2008). Orientando un cambio de actitud hacia las Ciencias Naturales y su enseñanza en profesores de Educación Primaria. Revista Electrónica de Enseñanza de las Ciencias, 7(3), 539- 568.

García Barros, S. (2016). Conocimiento científico conocimiento didáctico. una tensión permanente en la formación docente. Campo Abierto Revista de Educación, 35(1), 31-44.

García Barros, S. y Martínez Losada, C. (2001). Las ideas de los alumnos del CAP, punto de referencia para reflexionar sobre formación docente. Revista Interuniversitaria 
de formación del profesorado, 40, 97-110.

García-López, D. (2009). Análisis del Role Playing como habilidad social en el proceso de enseñanza-aprendizaje de los alumnos. Revista Digital Ciencia y Didáctica, 12, 3242.

Gil-Pérez, D., Furió, C., Valdés, P., Salinas, J., Martínez, J., Guisasola, G., González, E., Dumas-Carré, A., Coffard, M. y Pessoa, A. M. (1999). ¿Tiene sentido seguir discutiendo entre aprendizaje de conceptos, resolución de problemas de lápiz y papel y realización de prácticas de laboratorio? Enseñanza de las Ciencias, 17(2), 311-320.

Gil-Pérez, D. y Vilches, A. (2004). La contribución de la ciencia a la cultura ciudadana. Cultura y Educación, 16(3), 259-272.

Goleman, D. (1996). Inteligencia emocional. Barcelona: Cairos.

González, T., Mellado, V. y Ruiz, C. (2005). Las ideas alternativas sobre el periodo de oscilación del péndulo simple. Una actividad de resolución de problemas a través de trabajos prácticos colaborativos. VII Congreso Internacional de Enseñanza de las Ciencias. Granada, España.

Gunstone, R. F. y Northfield, J. (1994). Metacognition and learning to teach. International Journal of Science Education, 16(5), 523-537.

Gutiérrez, J. M. (2011). La formación inicial del profesorado de Secundaria. Del CAP al Máster. CEE Participación Educativa, 17, 96-107.

Harlen, W. y Holroyd, C. (1997). Primary teachers' understanding of concepts of science: Impact on confidence and teaching. International Journal of Science Education, 19(1), 93-105.

Hugo, D. V. (2008). Análisis del proceso de autorregulación de las Prácticas Docentes de futuras profesoras de ciencias focalizado en sus emociones. Tesis Doctoral inédita. Universidad Autónoma de Barcelona.

Huinker, D. y Madison, S. K. (1997). Preparing efficacius elementary teachers in science and mathematics: the influence of methods course. Journal of Science Teacher Education, 8(2), 107-126.

Inhelder, B. y Piaget, J. (1958). The Growth of Logical Thinking. Nueva York: Basic Book.

Izquierdo, M. (2013). La química ¿emociona? En V. Mellado, L.J. Blanco, A.B. Borrachero y J.A. Cárdenas (Eds.), Las Emociones en la Enseñanza y el Aprendizaje de las Ciencias y las Matemáticas (pp.307-328). Badajoz: DEPROFE.

Jarvis, T. y Pell, A. (2004). Primary teachers' changing attitudes and cognition during a two year science in-service programme and their effect on pupils. International Journal of Science Education, 26(14), 1787-1811. DOI: https://dx.doi.org/10.1080/ 0950069042000243763

Jiménez-Tenorio, N. y Oliva, J. M. (2016). Análisis reflexivo de profesores de ciencias de secundaria en formación inicial en torno a diferentes secuencias didácticas. Revista EUREKA de Enseñanza y Divulgación de las Ciencias, 13(2), 423-439. Recuperado de: http://hdl.handle.net/10498/18298

Koballa, T. y Glynn, S. M. (2007). Attitudinal and motivational constructs in science learning. En S. K. Abell y N. G. Lederman (Eds.), Handbook of Research on Science 
Education (pp.75-102). Mahwah, NJ: Lawrence Erlbaum.

Lee, O. (1995). Subject matter knowledge, classroom management, and instructional practices in Middle School science classroom. Journal of Research in Science Teaching, 32(4), 423-440.

Matthews, M. R. (2000) Time for Science Education: How Teaching the History and Philosophy of Pendulum Motion can Contribute to Science Literacy. New York: Plenum Publishers.

Matthews, M. R., Gauld, C. F. y Stinner, A. (Eds.). (2005). The pendulum: Scientific, historical, philosophical and educational perspectives. Springer Science \& Business Media.

Mellado, V., Borrachero, A. B., Brígido, M., Melo, L.V., Dávila, M.A., Cañada, F., Conde, M.C., Costillo, E., Cubero, J., Esteban, R., Martínez, G., Ruiz, C., Sánchez, J., Garritz, A., Mellado, L., Vázquez, B., Jiménez, R. y Bermejo, M. L. (2014). Las Emociones en la Enseñanza de las Ciencias. Enseñanza de las Ciencias, 32(3), 11-36. 11. DOI: https://dx.doi.org/10.5565/rev/ensciencias.1478

Mellado, V., Conde, M. C., Brígido, M., Costillo, E., Ruiz, C., Bermejo, M. L. y Fajardo, M. I. (2010). The educational change in science teachers. En A.D. Henshall y B.C. Fontanez (Eds.), Educational Change (pp.61-83). Nueva York: Nova Science Publishers, Inc.

Pekrun, R. (1992). The impact of emotions on learning and achievement: Towards a theory of cognitive/motivational mediators. Aplied Psychology: An International Review, 41(4), 359-376.

Pérez, M., Reyes, M. y Juandó, J. (2001). Afectos, emociones y relaciones en la escuela. Barcelona: Biblioteca de Aula.

Pontes, A. y Poyato, F. J. (2016). Análisis de las concepciones del profesorado de secundaria sobre la enseñanza de las ciencias durante el proceso de formación inicial. Revista EUREKA de Enseñanza y Divulgación de las Ciencias, 13(3), 705724. Recuperado de: http://hdl.handle.net/10498/18507

Pontes, A., Poyato, F. y Oliva, J. M. (2015). Concepciones sobre el aprendizaje en estudiantes del Máster de profesorado de Educación Secundaria del área de ciencia y tecnología. Profesorado. Revista de Currículum y Formación de Profesorado, 19(2), 225-243.

Porlán, R. y Rivero, A. (1998). El conocimiento de los profesores. Sevilla: Diada.

Powell, J. C. y Anderson, R. D. (2002). Changing teachers' practice: Curriculum materials and science education reform in the USA. Studies in Science Education, 37(1), 107136. DOI: https://dx.doi.org/10.1080/03057260208560179

Randi, J. (2004). Teachers as self-regulated learners. Teachers College Record, 106(9), 1825-1853.

Sanmartí, N. (2001). Enseñar a enseñar ciencias en secundaria: Un reto muy completo. Revista Interuniversitaria de Formación del Profesorado, 40(15), 31-48.

Sassi, E., Monroy, G. y Testa, I. (2005). Teacher training about real-time approaches: Research-based guidelines and training materials. Science Education, 89(1), 28-37. DOI: https://dx.doi.org/10.1002/sce.20041 
Shoffner, M. (2009). The place of the personal: Exploring the affective domain through reflection in teacher preparation. Teaching and Teacher Education, 25(6), 783789. DOI: https://dx.doi.org/10.1016/j.tate.2008.11.012

Smith, D. C. y Neale, D. C. (1989). The construction of subject matter knowledge in primary science teaching. Teaching and Teacher Education, 5(1), 1-20. DOI: https://dx.doi.org/10.1016/0742-051X(89)90015-2

Solbes, J. y Gavidia, V. (2013). Análisis de las Especialidades de Física y Química y de Biología y Geología del máster de profesorado de educación secundaria de la Universidad de Valencia. Revista EUREKA de Enseñanza y Divulgación de las Ciencias, 10(Extra), 582-593. Recuperado de: http://hdl.handle.net/10498/15615

Solís, E, Martín del Pozo, R., Rivero, A. y Porlán, R. (2013). Expectativas y concepciones de los estudiantes del MAES en la especialidad de Ciencias. Revista Eureka sobre Enseñanza y Divulgación de las Ciencias, 10(Extra), 496-513. Recuperado de: http://hdl.handle.net/10498/15610

Tobin, K. (1998). Issues and trends in the teaching of science. En B. J. Fraser y K. Tobin (Eds.), International Handbook of Science Education (pp.129-151). Dordrecht: Kluwer Academic Publishers.

Torrecilla, E. M., Martínez, F., Olmos, S. y Rodríguez, M. J. (2014). Formación en competencias básicas para el futuro profesorado de Educación Secundaria: Competencias informacionales y de resolución de conflictos. Revista de Currículum y Formación del Profesorado, 18(2), 189-208.

Uitto, M., Jokikokko, K. y Estola, E. (2015). Virtual special issue on teachers and emotions in Teaching and teacher education (TATE) in 1985-2014. Teaching and Teacher Education, 50, 124-135. DOI: https://dx.doi.org/10.1016/j.tate.2015.05.008

Valdés, R. y Valdés, P. (1999). Características del proceso de enseñanza-aprendizaje de la física en las condiciones contemporáneas. Enseñanza de las Ciencias, 17(3), 521531.

Wengraf, T. (2001). Qualitative Research Interviewing. Biographic Narrative and Semistructured Methods. Londres: Sage Publications.

White, R. T. y Mitchell, I. J. (1994). Metacognition and the quality of learning. Studies in Science Education, 23(1), 21-37.

Yanes, J. (2007). Las TIC y la Crisis de la Educación. Algunas Claves para su Comprensión. Chile: Biblioteca Digital Virtual Educa.

.Zachos, P. (2004). Pendulum Phenomena and the Assessment of Scientific Inquiry Capabilities. Science \& Education, 13(7-8), 743-75. DOI: https://dx.doi.org/ 10.1007/s11191-004-6179-3 